\title{
Factors associated with groin complications post coronary intervention
}

\author{
Patricia M. Suggs ${ }^{1}$, Sheila R. Reagan ${ }^{1}$, Faye C. Clements ${ }^{1}$, Sonya R. Hardin ${ }^{2}$. \\ 1. Caromont Health-Gaston Memorial Hospital, Gastonia, NC, USA. 2. School of Nursing, University of NC at Charlotte, \\ Charlotte, NC, USA.
}

Correspondence: Patricia M. Suggs. Address: CVSS Gaston Memorial Hospital, 2525 Court Drive Gastonia, NC 28054, USA. Email: suggsp@caromonthealth.org

Received: December 10, 2012

Accepted: January 29, 2013

Online Published: February 5, 2013

DOI : $10.5430 /$ cns.v1n1p26

URL: http://dx.doi.org/10.5430/cns.v1n1p26

\section{Abstract}

Background: The American College of Cardiology (ACC) registry identifies a mean vascular complication rate of $1.4 \%$ post coronary intervention. Poor sheath removal technique, anticoagulant use, and patient characteristics have been associated with groin complications.

Objectives: The objective of the study was to examine the relationship between nurse characteristics and femoral sheath removal complications post coronary intervention.

Method: Using a retrospective descriptive design, the study examined 467 patients who underwent coronary intervention. Twenty-eight nurses were included. Data collected from the medical record included use of anticoagulants, access points and nurse demographic. Data collected also included patient complications as defined by the ACC.

Results: Years in nursing, experience in pulling catheters, and multiple catheter changes were not associated with complications. The use of a combination of heparin and Integrilin during the procedure was associated with complications.

Conclusions: No relationship was found between nurse characteristics and complications. Collaboration of all team members can help identify patients most at risk for complications. Consideration of alternative vascular access points or anticoagulants for these patients might be beneficial.

\section{Key words}

Cardiac catheterization, Percutaneous coronary intervention, Groin complication, Management of arterial access site

\section{Introduction}

In 2007, the cost of preventing and treating heart disease in the U.S. was an estimated $\$ 286$ billion, which is higher than the cost for cancer or any other diagnostic group ${ }^{[1-3]}$. A percentage of this annual cost is associated with cardiac catheterization, a procedure commonly used to diagnose and treat patients with heart disease. Percutaneous coronary intervention (PCI) is also a commonly performed interventional procedure. Over one million cardiac catheterizations and over 600,000 percutaneous coronary interventions were reported to the American College of Cardiology (ACC), a national registry, in $2010^{[4,5]}$. 
Most patients recover from these procedures without incident and are discharged with self-care instructions within 24 hours. While the American College of Cardiology Registry identifies a mean vascular complication rate of 1.4\%, not all organizations are members of this registry, thus other reports in the literature range from $1 \%$ to $14 \%{ }^{[6-9]}$.

The use of anticoagulants to minimize clot formation during the cardiac catheterization and the use of platelet inhibition agents to decrease stent restenosis raise the risk of groin bleeding complications post procedure ${ }^{[10]}$. Vascular complications include bleeding at the access site, hematoma, retroperitoneal bleeding, and pseudoaneurysms or arteriovenous fistula formation ${ }^{[10]}$. Local complications at the sheath introduction site are among the most common problems seen after cardiac catheterization procedures ${ }^{[11]}$.Bleeding, bruising, or hematoma at the sheath site can occur if sufficient pressure is not applied manually, with a mechanical compression device, or with vascular closure devices ${ }^{[12]}$.

A hematoma is a collection of blood within the soft tissues of the upper thigh or lower abdomen. It can occur if the sheath is removed prior to proper hand positioning and timely compression or prior to sheath removal if multiple attempts were made for vascular access. Manual compression requires the use of the two or three fingers compressing 1 to $2 \mathrm{~cm}$ above the puncture site directly for approximately 20 minutes. If bleeding from the hematoma is controlled with manual compression, the hematoma will usually resolve within 1-2 weeks as the blood is reabsorbed from the soft tissues. Another option is to use a mechanical compression device, which is a hand-free approach that does not require a nurse to be at the bedside consistently. And lastly a vascular closure device can be inserted into the site to close the opening. These devices include patches, or plugs that are inserted post procedure by a health care provider. While vascular closure devices result in less need for compression they have not been found to decrease bleeding or vascular complications ${ }^{[13]}$.

A retroperitoneal hematoma is an accumulation of blood in the retroperitoneal space. Unlike other bleeding sites, the retroperitoneum can harbor a large volume of blood with few external manifestations until hypovolemia occurs, leading to delayed recognition, added morbidity, and a potentially fatal result ${ }^{[14]}$. Symptoms can include a groin hematoma, fall in hgb/hct, hypotension, abdominal pain, nausea/vomiting, diaphoresis, flank ecchymosis, and bradycardia.

Pseudoaneurysm occurs when there is a disruption in the intimal arterial wall resulting in a blood filled sac that is contained by the soft tissues around the artery ${ }^{[15]}$. This complication can appear within12-72 hours post procedure. The clinical presentation includes pain, swelling, and severe bruising at the arterial puncture site. Compression therapy is appropriate for pseudoaneurysms that are less than $2 \mathrm{~cm}$. Ultrasound guided thrombin injection at the site is required for those that cannot be resolved with compression therapy ${ }^{[16,17]}$. Femoral pseudoaneurysms may occur on up to $8 \%$ of vascular interventional procedures ${ }^{[14]}$.

Arterio-venous (AV) fistula occurs when bleeding from the arterial puncture tracks into the adjacent venous puncture, forming an arteriovenous fistula. Many of these fistulas are small and resolve spontaneously. AV fistula is often associated with a low groin puncture and can occur during manual compression. It is typically asymptomatic but can result in numbness due to a reduced flow of blood and reduced distal pulses following catheterization.

\subsection{Risk factors for groin complications}

Numerous studies have focused on identifying risk factors associated with complications of cardiac catheterization. Risk factors associated with vascular complications include being older and female, small stature, obese, coexisting condition of hypertension and/or renal failure, use of a large sheath, prolonged sheath time and excessive coagulation ${ }^{[1,10,11,18-20]}$. Difficulty of femoral artery catheter insertion due to artery size has been implicated as one risk factor. Small artery size has been associated with female gender, current and former smoking and the presence of peripheral vascular disease $^{[18]}$. Repeated cardiac catheterizations and use of vascular closure devices (VCDs) have been found to cause change in the femoral artery size. Women with peripheral vascular disease who are current or former smokers also have smaller femoral artery diameters. Men and women who have used statins have larger femoral arteries than those who did 
not ${ }^{[18]}$. Studies have recommended the avoidance of closure devices with patients with severe arteriosclerosis ${ }^{[21,22]}$. Persistent oozing around the site has also been noted in these patients ${ }^{[21]}$.

An increased risk of retroperitoneal hematomas has been found with females, large sheath size, left groin access and low body surface area ${ }^{[24,25]}$. Spontaneous retroperitoneal bleeding has been reported as a complication in individuals who are fully heparinized and coumadinized as well as patients who receive enoxaparin. A high index of suspicion is necessary if the patient displays any of the signs and symptoms that suggest major hemorrhage. It appears that those at highest risk are patients who receive doses approaching $1 \mathrm{mg} / \mathrm{kg}$ subcutaneously every 12 hours, have renal impairment, are of advanced age ${ }^{[21]}$ and receive concomitant medications that can affect hemostasis. On average, a retroperitoneal hematoma occurs within 5 days of therapy with enoxaparin. In high-risk patients, enoxaparin activity (anti-factor Xa) should be carefully monitored.

\subsection{Nursing site management}

A number of studies have focused on the nursing management of patients during femoral sheath removal ${ }^{[27-31]}$. One study reported reduction in hematoma rate from $12 \%$ to $1 \%$ through performance improvement projects. This was accomplished by shifting post procedural care after peripheral arterial interventional procedures from the cardiac catheterization laboratory to the inpatient vascular surgical unit with specially trained acute care nurses. The study showed an average manual compression rate of 24 minutes ${ }^{[28]}$. Nurses with training specific to care of these patients allow for improved patient outcomes through careful monitoring of vital signs and cardiac rhythm, and assessment of vascular access site.

Two European studies have recommended yearly repetition of training and observation of skills be implemented to improve patient outcomes ${ }^{[29,30]}$. One proposed the use of a checklist instrument to evaluate nurse performance that included two categories with a total of 10 elements and 65 items on sheath removal. The category "Conditions" consisted of three elements, Activated Clotting Time, Urinary, Groups at risk. The other seven elements were grouped into the category of "Performance." This category included Preparation, Controls, Information, Position, Sheath Removal, Bandage and Instructions ${ }^{[30]}$. This instrument was used to measure level of nurse skill in sheath removal process. Another study supported the use of a nurse-led protocol in the form of a decision making tree in a post catherization laboratory. The protocol used pulse oximetry on the ipsilateral foot. Once the pulse was no longer sensed, the sheath was removed, with digital pressure applied for a further 2 minutes and slowly released over a 5 minute period until the pulse returned to the foot. If bleeding was detected a further 5-10 minutes of manual pressure was applied until stable. All patients laid flat for 60 minutes and then were elevated to 45 degrees for another 60 minutes. The use of this protocol resulted in minor hematomas (1.6\%) and the absence of major complications among a total of 526 subjects ${ }^{[29]}$.

Another study recommended a nurse to patient ratio of 1:5 or less, removal of sheaths as soon as possible post procedure, and premedication of patients ${ }^{[27]}$. Sheath removal by nurses has been found to result in a lower occurrence of bleeding and a higher rate of premedication prior to removal ${ }^{[32]}$. The use of manual pressure to remove sheaths led to fewer complications than sheath removal using mechanical devices such as the Compressar or Femostop ${ }^{[31]}$.

\subsection{Nurse characteristics}

Factors associated with complications of cardiac catheterizations have often been examined from the perspective of patient characteristics. Few studies have looked at complications in relation to nurse characteristics. Nurse education level, certification status and years of experience were part of the data collected for this study. Multiple studies have attempted to link certification and level of education to positive patient outcomes ${ }^{[33,34]}$. Units with higher percentage of nurses certified in their specialty have been linked in some studies to positive patient outcomes ${ }^{[33]}$. However, no relationship was noted in this study between nurse certification and patient outcomes. 


\subsection{Conceptual framework}

The Donabedian's conceptual framework ${ }^{[35,36]}$ holds that the structure of care affects the processes of care and that both structure and process, in turn, affect the outcomes of care. The concept of structure refers to the supply, skill level and education/certification status of nurses. A motivation for focusing on structure is the premise that the personnel can be a strong determinant of care quality.

Process indicators measure aspects of nursing care such as frequency of assessment and intervention. In this study, intervention involves the manual compression at the femoral site post cardiac catherization.

Patient outcomes are those that improve if there is a greater quantity or quality of nursing care (e.g., bleeding and hematomas). The outcomes examined in this study were cardiac femoral catheterization of bleeding, hematoma, retroperitoneal bleeding and pseudoaneurysms or arterial venous fistula formation. The American College of Cardiology defines bleeding as a $3 \mathrm{gm}$ drop in hemoglobin or a hematoma as $10 \mathrm{~cm}$ or greater ${ }^{[4]}$. Both retroperitoneal and pseudoaneurysms or arterial venous fistula formation were documented by computerized tomography scan and/or in the record.

This framework is utilized in the study to support the examination of the relationship of nurse characteristics to complications associated with vascular access of a femoral artery for percutaneous coronary intervention.

\section{Research questions}

The research questions for this study were 1) Do years of nursing experience correlate with groin complications? 2) Does experience in pulling sheaths correlate with groin complications? 3) Does nursing education level correlate with groin complications?

\subsection{Design}

A retrospective descriptive correlational design was approved by the facility's Institutional Review Board (IRB) and the local state university IRB, equivalent to ERB, ethical review board.

\subsection{Setting}

A 435-bed, acute care hospital located in the western part of North Carolina was the setting for the study. This facility has a 3 room catheterization laboratory that performs 1,910 diagnostic cardiac catheterizations and approximately 500 percutaneous coronary interventions annually. In 2009 the rate of complications at a vascular site was $4.0 \%$. Twenty eight nurses work in the unit. Outpatients are prepared for and recover from cardiac catheterization lab procedures in a 16 bed Cardiovascular Short Stay (CVSS) unit. These procedures include cardiac catheterization, percutaneous coronary intervention, renal or peripheral angiography, and pacemaker or implanted cardiac defibrillator placement. When indicated, CVSS staff members discontinue femoral artery sheaths post procedure. The facility uses a standard procedure for sheath removal which includes applying manual pressure 1 to $2 \mathrm{~cm}$ above the insertion site for 20 minutes or until hemostasis is achieved, followed by 6 to 8 hours of bed rest. Post operatively, nurses palpate and visually inspect the groin site every 15 minutes $x 4$, then every 30 minutes x 2 , then hourly x 4 hours ${ }^{[26]}$. The hospital policy for femoral artery sheath removal is based on the procedure outlined in the AACN Procedure Manual for Critical Care $5^{\text {th }}$ edition ${ }^{\text {[26] }}$.

\subsection{Sample}

The sample was a convenience sample that included all of the 467 percutaneous coronary interventions conducted over a 12-month period of time; no peripheral vascular cases were included. The 28 nurses in the study were the full complement of employees working in the unit. 
Nurses accepted as members of the staff on CVSS must have a minimum of 1 year of critical care experience. A new staff member is assigned a preceptor who is an experienced nurse on CVSS. Before caring for a patient, the staff member is expected to become familiar with the femoral arterial sheath removal policy. Familiarity with policy prepares the staff member to assess for common complications such as vaso-vagal reactions, bleeding or hematoma formation at the sheath site. New CVSS staff members must then demonstrate successful sheath removal while being observed by the preceptor. Once new staff members have successfully demonstrated this skill three times, they are able to perform the procedure independently. All staff members are encouraged to enlist the assistance of coworkers for any concerns with this procedure.

Nurse characteristics were chosen based upon the available data. The majority of nurses had a BSN ( $\mathrm{n}=19,68 \%)$, with only 5 holding an Associate Degree ( 2 year) and 4 Diploma graduates ( 3 year degree). The experience of removing femoral sheaths ranged from less than 1 year to over 4 years. 10 nurses $(36 \%)$ had less than 1 year of experience pulling sheaths, 12 (43\%) had 1-4 years' experience and $6(32 \%)$ had over 4 years of experience. The majority of nurses in the study had less than 25 sheath pulls (54\%) and held no certification (n=17, 61\%). Employment status was 15 (54\%) full time and $13(46 \%)$ part time or per diem.

\subsection{Method}

This retrospective study extracted data from the electronic medical record. Data on variables associated with the PCI were collected including sheath size, whether or not the sheath was changed during procedure, placement of sheath (left or right side), type of anticoagulation, length of time manual pressure was held, presence of hematoma, bleeding, or retroperitoneal bleed. American College of Cardiology definitions and nursing documentation were utilized to identify types of groin complication examined. Variables of individuals with complications were examined and included age, BMI, gender, race, and diabetic status. Demographic data of nurses who removed sheaths were analyzed. SPSS Edition 17 was utilized for data analysis ${ }^{[37]}$.

\subsection{Results}

\section{Data}

The data analyzed included sheath size, whether the sheath was changed, side of catheter insertion, type of anticoagulant used, number of minutes of pressure applied to groin site, and whether a sandbag was used to stabilize bleeding. Most sheaths were a size $6(n=467,91.4 \%)$, not changed and with right side insertion $(n=430,92.1 \%)$. For the majority of sheaths 20 minutes of pressure to achieve hemostasis was recorded $(n=348,74.5 \%)$. Most patients received heparin and eptifibatide $($ Integrilin $\AA)(n=235,50.3 \%)$ or bivalirudin $\left(\right.$ Angiomax $\left.{ }^{\circledR}\right)(n=143,30.6 \%)$ during the procedure.

Post catheterization complications were minimal given the number of catheterizations. Only $3.4 \%(\mathrm{n}=16)$ had bleeding, $2.8 \%(\mathrm{n}=13)$ had a hematoma and a pseudo-aneurysm occurred in only $2(0.4 \%)$ patients. No retroperitoneal bleeding occurred during the study period. The hematoma cases were examined and findings are displayed in Table 1 . There were 8 men and 5 women with hematomas. Of these 13, eight were obese and only 4 were diabetic.

Table 1. Cases with Hematoma

\begin{tabular}{llllll}
\hline Gender & Frequency & Ages $>$ 65 & Diabetes & Hyperlipidemia & Obesity \\
\hline Male & $8(61.5 \%)$ & $3(60 \%)$ & $3(75 \%)$ & $7(64 \%)$ & $4(50 \%)$ \\
Female & $5(38.5 \%)$ & $2(40 \%)$ & $1(25 \%)$ & $4(36 \%)$ & $4(50 \%)$ \\
Total & $13(100 \%)$ & $5(100 \%)$ & $4(100 \%)$ & $11(100 \%)$ & $8(100 \%)$ \\
\hline
\end{tabular}

A number of variables were significantly correlated; they are shown in Table 2 . The minutes of holding pressure at the groin site was significantly correlated with a hematoma $(\mathrm{r}=.117)$. The size of the catheter was significantly correlated with 
catheter change $(\mathrm{r}=.264)$ and sandbag use $(\mathrm{r}=.108)$. The use of a sand bag was positively correlated with the minutes of pressure used for groin management $(\mathrm{r}=.134)$. No significant difference was found in the frequency of hematomas between those patients who received heparin only or in combination with Integrilin and those receiving other anticoagulants. Pseudoaneurysm was correlated with type of anticoagulant utilized $(\mathrm{r}=.098)$. There were two pseudoaneurysms in the study. Both had bivalirudin (Angiomax ${ }^{\circledR}$ ) used as the anticoagulant. The nurses who pulled the sheath on these patients had more than 25 sheath pulls and were baccalaureate prepared; one was certified and one was part time.

Table 2. Correlations of Complications and Risk Factors

\begin{tabular}{|c|c|c|c|c|c|c|c|}
\hline & $\begin{array}{l}\text { Size } \\
\text { sheath }\end{array}$ & $\begin{array}{l}\text { Catheter } \\
\text { exchanged }\end{array}$ & $\begin{array}{l}\text { Side } \\
\text { used }\end{array}$ & $\begin{array}{l}\text { Sand Bag } \\
\text { used }\end{array}$ & Hematoma & Pseudoaneurysm & $\begin{array}{l}\text { Minutes of } \\
\text { pressure }\end{array}$ \\
\hline Size sheath & 1 & $.264^{* *}$ & .075 & $.108^{*}$ & .064 & -.002 & .053 \\
\hline $\begin{array}{l}\text { Catheter } \\
\text { exchanged }\end{array}$ & $.264^{* *}$ & 1 & .061 & -.010 & -.001 & -.019 & .033 \\
\hline Side & .075 & .061 & 1 & .023 & $.095^{*}$ & -.019 & -.027 \\
\hline $\begin{array}{l}\text { Heparin } \\
\text { Vs } \\
\text { angiomax }\end{array}$ & -.020 & -.078 & -.027 & .071 & -.046 & $.098^{*}$ & .068 \\
\hline Sand bag use & $.108^{*}$ & -.010 & .023 & 1 & .033 & .086 & $.134^{* *}$ \\
\hline Hematoma & .064 & -.001 & $.095^{*}$ & .033 & 1 & -.011 & $.117^{*}$ \\
\hline $\begin{array}{l}\text { Number of } \\
\text { sheaths utilized }\end{array}$ & .012 & -.046 & -.025 & -.034 & -.069 & .028 & .007 \\
\hline
\end{tabular}

Note: Pearson Correlation reported ${ }^{* *} \mathrm{p}<.01 ;{ }^{*} \mathrm{p}<.05$

A Chi square test was performed on groin complications and nurse demographic variables. No significant associations were found between groin complications and nurses certified, education, years of experience of pulling sheaths, or employment status (full time, part time, per diem). However, years of experience as a nurse were significantly associated with hematoma, probably due to the large number of sheath pulls by the most experienced nurses.

\subsection{Limitations}

Study limitations include the use of a retrospective analysis, a secondary data base, and lack of reliability testing for the data stored in the database. Also, data on co-morbidities, patient BMI, and registered nurse stature (height) were not available and thus the influence of these factors could not be examined. Other nurse characteristics that might influence vascular complications after percutaneous coronary intervention remain elusive, such as accuracy of nursing documentation. Another limitation is that catheterization reports were not examined to see if a hematoma started in the catheterization laboratory. Lastly, nurse technique and physician skill in inserting the catheter were not controlled for in the study.

\section{Clinical implications of major findings}

Treatment of hematoma is designed to control bleeding. After a sheath is removed, direct pressure is applied until hemostasis is reached. If a hematoma develops or there is delay in hemostasis, greater than 20 minutes of pressure may be needed to control bleeding ${ }^{[26]}$. In this study, some cases documented 15 minutes of manual pressure to reach hemostasis while the majority of cases documented 20 minutes of manual pressure to reach hemostasis.

The use of heparin was not correlated with groin complications in this study. Most patients received heparin and eptifibatide (Integrilin ${ }^{\circledR}$ ) or bivalirudin (Angiomax ${ }^{\circledR}$ ). Heparin with the addition of glycoprotein IIb/IIIa inhibitors and 
eptifibatide (Integrilin ${ }^{\circledR}$ ) was correlated with increased bleeding. Similar findings were noted in the RIVAL study ${ }^{[39]}$, which also correlated bleeding with overall mortality. Pseudoaneurysm is a complication that presents 12-72 hours post procedure. For that reason it may be under-reported because it is sometimes discovered post discharge ${ }^{[14,17,39]}$. In this study, pseudoaneurysm was correlated with the anticoagulant used, bivalirudin (Angiomax ${ }^{\circledR}$ ). Therefore, patients receiving heparin and glycoprotein IIb/IIIa inhibitors (ReoPro $\AA$ ) or heparin and bivalirudin (Angiomax $\left.{ }^{\circledR}\right)$ may warrant increased vigilance in assessing for bleeding and hematoma formation. This patient population may also require longer compression time to decrease the risk of complications.

Sandbag use was correlated with sheath size. If an RN is concerned about the site, a sandbag may be used for support. However, more experienced RNs are aware of an evidence based move away from utilization of sandbags; therefore increased experience was correlated negatively with sandbag use.

\subsection{Research implications}

Sheath size was correlated with sheath change in this study. The most commonly used sheath size is $6 \mathrm{~F}$ since it is large enough to accomplish most procedures, but small enough for rapid hemostasis ${ }^{[1]}$. At times a change in sheath size is necessary for further testing or intervention. While many assume that a change in sheath would increase the incidence of hematoma that was not the case in this study. Most cardiac catheterizations occur with a right groin approach. However the left groin is used if access is not possible on the right side due to peripheral vascular disease. Insertion of the sheath into the left groin was correlated with hematoma in this study. While the literature reviewed does not discuss side of sheath insertion as a risk for complications, peripheral vascular disease has been cited as a risk factor ${ }^{[38]}$. More study is needed to clarify causality in this regard.

The number of years pulling sheaths was correlated with certification, which demonstrates a high level of competence or expertise in a particular arena ${ }^{[41]}$. Workplace empowerment and certification have been associated in the literature ${ }^{[33,41]}$. Perhaps experience with a specialized skill set such as vascular access site assessment and arterial sheath removal lends itself to a sense of empowerment and the drive to support these skills with certification. Further research is needed to examine nurse characteristics and patient outcomes among this population of patients.

\section{Summary}

The primary goals for groin management after cardiac catheterization procedures are achievement of hemostasis and assessment of the site for complications ${ }^{[39,1]}$. A complication can occur when the sheath is inserted, while the sheath is in place, during removal, or hours later. Factors that influence complication are multi-level ${ }^{[40]}$. Therefore interventional cardiologists, cardiac catheterization staff and nurses caring for these patients must work together to prevent complications, when possible, and treat complications when they occur ${ }^{[41]}$. Diligent assessment and monitoring are required to meet these goals ${ }^{[42]}$. Risk factors associated with vascular complications include older age, female gender, hypertension, large sheath size, prolonged sheath time, renal failure, and excessive anticoagulation ${ }^{[39,16]}$. Nurses with specialized training are needed to assess, identify and manage vascular complications ${ }^{[43]}$.

\section{References}

[1] Hamel HJ. Femoral artery closure after cardiac catheterization. Critical Care Nurse. 2009; 29(1): 39-46. PMid:19182279 http://dx.doi.org/10.4037/ccn2009157

[2] Center for Disease Control and Prevention. Available from http://www.cdc.gov/nchs/faststats/lcod.htm. Accessed May $26,2011$.

[3] USA Today. Available from

http://www.usatoday.com/yourlife/health/medical/heartdisease/2010-12-17-death-rate-from-heart-disease-drops N.htm. Accessed May 26, 2011.

[4] American College of Cardiology. Available from https://www.ncdr.com/webncdr/DefaultCathPCI.aspx. Accessed June 3, 2011. 
[5] American Hospital Association. Available from http://www.aha.org/aha/resouce-center/Statistics-and-Studies/fast-facts.html. Accessed May 26, 2011.

[6] Morton BC, Beanlands DS. Complication of cardiac catheterization: one center's experience. Can Med Assoc J. 1984; 131: 889-892. PMid:6488120

[7] Diethrich EB, Pierce SA. Outpatient cardiac catheterization and arteriography: twenty month experience at the Arizona Heart Institute. Cardiovascular Disease Bulletin of Texas heart Institute. 1981; 8(2):195-204.

[8] Yetkin U, Ozelci A, Akyuz M,Goktogan T, Yurekli I, Gurbuz A. Surgical approach to a giant post cardiac catheterizations psuedoaneurysm after unsuccessful duplex ultrasound guided compression. Internet Journal of Cardiology. 2010; 8(2):12.

[9] Batyraliev T, Ayalp MR, Sercelik A, et al. Complications of cardiac catheterization: a single-center study. Angiology. 2005; 56(1): 75-80. PMid:15678259 http://dx.doi.org/10.1177/000331970505600110

[10] Lins S, Guffey D, VanRiper S, Kline-Rogers E. Decreasing vascular complications after percutaneous coronary interventions partnering to improve outcomes. Critical Care Nurse. 2006; 29(1):39-46.

[11] Waksman R, King III SB, Douglas JS, et al. Predictors of groin complications after balloon and new device coronary intervention. Am J Cardiology. 1995; 75:886-889. http://dx.doi.org/10.1016/S0002-9149(99)80681-X

[12] Shaffer RB. Arterial and venous sheath removal. In: Wiegand DJ, Carlson KK, eds. AACN Procedure Manual for Critical Care. 5th ed. St Louis, MO: Elsevier Saunders; 2005: 602-609.

[13] Safian RD, Freed MS. The Manual of Interventional Cardiology. 3rd ed. Royal Oak, MI: Physician Press; 2001.

[14] Tisi PV, Callam MJ. Treatment for femoral pseudoaneurysm. Cochrane Database System Review. 2009 (2): CDOO4981.

[15] Ludde M, Krumsdorf U, Zehelein J, et al. Treatment of iatrogenic femoral pseudoaneurysm by ultrasound guided compression therapy and thrombin injection. Angiology. 2007; 58:435-439. PMid:17875956 http://dx.doi.org/10.1177/0003319706294608

[16] Goldshtein L, Rassin M, Cohen I, Silner D. Managing pseudoaneurysm after cardiac catheterization. Nursing 2006. 2006; 36(5):64.

[17] Lamb K. Pseudoaneurysm and arteriovenous fistula simultaneously after catheterization. J Diagnostic Medical Sonography. 2007; 23:208-211. http://dx.doi.org/10.1177/8756479307304110

[18] Tiroch KA, Mathenmy ME, Resnic FS. Quantitative impact of cardiovascular risk factors and vascular closure devices on the femoral artery and repeat cardiac catheterization. AM Heart J. 2010 January; 159(1). PMid:20102878 http://dx.doi.org/10.1016/j.ahj.2009.10.023

[19] Ernits M, Mohan PS, Fares LG II, Hardy H III. A retroperitoneal bleed induced by enoxaparin therapy. Am Surg. 2005 May; 71(5):430-433.PMid:15986976

[20] Hanlon C, Rosenthal J. The Pennsylvania Learning Exchange: Helping States Improve and Integrate Patient Safety Initiatives, Summary Report. 2007. National Academy for State Health Policy, December 2007.

[21] Kadner A, Schmidli J, Schwegler I, et al. Complications associated with the arterial puncture closure device-angio-seal. Vascular and endovascular surgery. 2008; 42(1):225-208. PMid:18230871 http://dx.doi.org/10.1177/1538574407312657

[22] Koreny M, Riedmūller E, Nikfardjam M, Siostrzonek P, Müller M. Arterial puncture closing devices compared with standard manual compression after cardiac catheterization: systematic review and met-analysis. JAMA. 2004 Jan 21; 291(3):350-357. PMid:14734598 http://dx.doi.org/10.1001/jama.291.3.350

[23] Wong P, Harding S, Walters D, Hull ML, Jang IK. Vascular complications after hemostatic puncture closure device (Angio-seal) are not higher in over weight patients. Journal of Invasive Cardiology. 2001 Sept; 13(9):623-625. PMid:11533497

[24] Frank JJ, Kamalakannan D, Kodenchery M, Savoy-Moore ST, Rosman H. Retroperitoneal hematoma in patients undergoing cardiac catheterization. Journal of Interventional Cardiology. 2010; 23(6):567-574. PMid:20796167 http://dx.doi.org/10.1111/j.1540-8183.2010.00583.x

[25] Sabo J, Chlan LL, Savik K. Relationships among patient characteristics, comorbidities and vascular complications post percutaneous coronary intervention. Heart Lung. 2008: 37:190-195. PMid:18482630 http://dx.doi.org/10.1016/j.hrtlng.2007.06.001

[26] Weigand D, Carlsen K. AACN Procedure Manual for Critical Care.5th edition. Elsevier Inc.; 2005: 602-609.

[27] Juran NB, Rouse CL, Smith DD, O'Brien MA, DeLuca SA, Sigmon K, the SANDBAG Coordinators. Nursing Interventions to decrease bleeding at the femoral access site after percutaneous coronary intervention. American Journal of Critical Care. 1999; 8:303-313. PMid:10467467

[28] Capasso VA, Codner C, Nuzzo-Meuller G, Cox EM, Bouvier S. Peripheral arterial sheath removal program: A performance improvement initiative. Journal of Vascular Nursing. 2006; 24:127-132. PMid:17141131 http://dx.doi.org/10.1016/j.jvn.2006.09.001 
[29] Liew R, Lidder S, Gorman E, Gray M, Deaner A, Knight C. Very low complication rates with a manua, nurse-led protocol for femoral sheath removal following coronary angiography. European Journal of Cardiovascular Nursing. 2007; 6:303-07. PMid:17467341 http://dx.doi.org/10.1016/j.ejcnurse.2007.03.001

[30] Schiks I, Schoonhoven L, Verheught F, Aengevaeren W, Van Achterberg T. Performance evaluation of arterial femoral sheath removal by Registered Nurses after PCI. European Journal of Cardiovascular Nursing. 2007; 6:172-177. PMid:16997633 http://dx.doi.org/10.1016/j.ejcnurse.2006.08.001

[31] Benson LM, Wunderly D, Perry B, Kabboord J, Wenk T, Birddall B et al. Determining best practice:Comparison of three methods of femoral sheath removal after cardiac interventional procedures. Heart Lung. 2005; 34:115-21. PMid:15761456 http://dx.doi.org/10.1016/j.hrtlng.2004.06.011

[32] Peet GI, McGrath MA, Brunt JH, et al. Clinical rounds.Femoral arterial sheath removal after PTCA: a cross-Canada survey. Can J Cardiovasc Nurs. 1995; 6:13-19. PMid:8573276

[33] Krapohl G, Manojlovich M, Redman R, Zhang L. Nursing specialty certification and nursing-sensitive patient outcomes in the intensive care unit. American Journal of Critical Care. 2010; (19)6:490-498. PMid:21041193 http://dx.doi.org/10.4037/ajcc2010406

[34] Coleman EA, Coon SK, Lockhart K, Kennedy RL, Montgomery R, Copeland N. et al. Effect of certification in oncology nursing on nursing-sensitive outcomes. Clinical Journal of Oncology Nursing. 2009; (13)2: 165-172. http://dx.doi.org/10.1188/09.CJON.165-172

[35] Donabedian A. The quality of care: How can it be assessed? Journal of the American Medical Association. 1988:260,1743-1748. PMid:3045356 http://dx.doi.org/10.1001/jama.1988.03410120089033

[36] Donabedian A. The role of outcomes in quality assessment and assurance. Quality Review Bulletin. 1992:11, 356-360.

[37] SPSS. SPSS for Windows, REL 17.0.0. Chicago, Ill: SPSS, INC. 2009.

[38] Jolly SS, Yusuf S, Cairns J, et al. Radial versus femoral access for coronary angiography and intervention in patients with acute coronary syndromes (RIVAL): a randomized, parallel group multicenter trial. The Lancet. Published Online 04 April, 2011. http://dx.doi.org/10.1016/S0140-6736(11)60404-2

[39] Dumont CJP, Keeling AW, Bourguignon C, Sarembock IJ, Turner M. Predictors of vascular complications post diagnostic cardiac catheterization and percutaneous coronary interventions. In: Dimensions of Critical Care Nursing. Philadelphia, PA: Lippincott Williams \& Wilkins; 2006; 25(3):137-142.

[40] Frank-Stromberg M, Ward S, Hughes L, et al. Does certification status of oncology nurses make a difference in patient outcomes? Oncology Nursing Forum. 2002; 29(4):665-672. PMid:12011913 http://dx.doi.org/10.1188/02.ONF.665-672

[41] Shoulders-Odom B. Management of patients after percutaneous coronary interventions. Critical Care Nurse. 2008 ; $28(5): 26-39$. PMid:18827085

[42] Gonzales L, Fields W, McGinty J, Gallo A. Quality improvement in the catheterization laboratory redesigning patient flow for improvement outcomes. Critical Care Nurse. 2010; 30(2):25-32. PMid:20360448 http://dx.doi.org/10.4037/ccn2010832

[43] Leeper B. Nursing outcomes: percutaneous coronary interventions. Journal of Cardiovascular Nursing. 19(5):346-53. PMid:15495895

[44] Davis C, VanRiper S, Longstreet J, Moscucci M. Vascular complications of coronary interventions. Heart Lung. 1997; 26(2):118-127. http://dx.doi.org/10.1016/S0147-9563(97)90071-6 